\title{
IMPLEMENTASI MANAJEMEN BANDWIDTH DAN FILTERING WEB ACCESS CONTROL MENGGUNAKAN METODE ADDRESS LIST
}

\author{
Bayu Prasetyo ${ }^{1}$, Anggi Puspitasari², Raudah Nasution ${ }^{3}$ \\ Program Studi Teknik Informatika, STMIK Nusamandiri ${ }^{1}$ \\ Program Studi Sistem Informasi, Fakultas Teknologi Informasi 2,3 \\ Universitas Bina Sarana Informatika \\ bayuupw666@gmail.com¹ , anggi.apr@bsi.ac.id ${ }^{2}$,raudah.rhn@bsi.ac.id ${ }^{3}$
}

\begin{abstract}
Abstrak, CV Cahaya Indo Alumunium menggunakan internet sebagai sarana untuk melakukan promosi, pemasaran, penjualan, dan komunikasi yang praktis kepada pelanggan maupun relasi kerja. Tetapi pada jaringan CV Cahaya Indo Alumunium belum menerapkan manajemen bandwidth dalam membagi koneksi internet kepada komputer karyawannya. Tanpa adanya manajemen bandwidth banyak komputer yang menggunakan internet secara tidak beraturan sehingga menyebabkan komputer yang lain tidak mendapat jatah bandwidth yang adil. Karena koneksi internet yang tidak merata, hal ini menyebabkan terganggunya operasional perusahaan, sehingga berdampak pada ruginya perusahaan baik dari material maupun manajerial. Belum adanya manajemen bandwidth pada CV Cahaya Indo Alumunium diperparah dengan banyaknya staff dan karyawan yang menggunakan internet tidak untuk mengakses kebutuhan yang berhubungan dengan pekerjaan. Masih banyak staff dan karyawan yang menggunakan internet untuk mengakses situs-situs social media seperti facebook, twitter, maupun situs-situs lainnya yang tidak ada kaitannya dengan pekerjaan, membuat tidak efektifnya internet yang ada pada CV Cahaya Indo Alumunium tersebut. Oleh sebab itu untuk memaksimalkan akses internet yang terdapat pada CV Cahaya Indo Alumunium diperlukan manajemen bandwidth dan filtering web access control. Dengan adanya manajemen bandwidth dan filtering web access control diharapkan semua komputer dapat menggunakan internet dengan lancar dan stabil walaupun semua unit komputer menggunakan internet dalam waktu yang bersamaan serta dengan adanya manajemen bandwidth dan filtering web access control diharapkan dapat meningkatkan produktifitas staff/karyawan dalam bekerja.
\end{abstract}

\section{Kata Kunci: Manajemen Bandwidth, filtering, Web Access Control}

Abstract, CV Cahaya Indo Alumunium using the internet as a means of promoting, marketing, sales, communication and practical to the customer as well as the working relationship. But on the network of CV Cahaya Indo Alumunium yet implement bandwidth management in leveraging the internet connection of a computer to its employees. In the absence of bandwidth management multiple computers that use the internet for irregular causing the other computers are not guaranteed a fair bandwidth. Because the internet connection that is uneven, this causes a disruption of the company's operations, so the impact on the harm the company both from a material or managerial. Yet the existence of bandwidth management in CV Cahaya Indo Alumunium compounded with the large number of staff and employees who don't use the internet to access job-related needs. There are still plenty of staff and employees who use the internet to access social media sites such as facebook, twitter, and other sites that have nothing to do with the job, making not effectively the internet on $C V$ Cahaya Indo Alumunium. Therefore, to maximize the internet access $C V$ Cahaya Indo Alumunium required bandwidth management and filtering web access control. With the bandwidth management and filtering web access control expected all computers can use the internet with a smooth and stable even though all computer units using the internet at the same time as well as with the management of bandwidth and filtering web access control is expected to increase the productivity of stafflemployees in work.

Keywords: Bandwidth Management, filtering, Web Access Control ,. 


\section{PENDAHULUAN}

Pada saat ini internet sudah menjadi sebuah kebutuhan yang sangat penting bagi manusia. Sekarang ini, hampir semua informasi dapat diakses dengan menggunakan internet, sehingga memudahkan dalam mencari dan mendapatkan informasi. Internet sudah menjadi kebutuhan pokok bagi suatu lembaga, instansi pemerintahan, maupun perusahaan.

CV Cahaya Indo Alumunium adalah perusahaan yang bergerak pada bidang jasa dan supplier alumunium profile dan powder coating. CV Cahaya Indo Alumunium menggunakan internet sebagai sarana untuk melakukan promosi, pemasaran, penjualan, dan komunikasi yang praktis kepada pelanggan maupun relasi kerja. Tetapi pada jaringan CV Cahaya Indo Alumunium belum menerapkan manajemen bandwidth dalam membagi koneksi internet kepada komputer karyawannya.

Tanpa adanya manajemen bandwidth banyak komputer yang menggunakan internet secara tidak beraturan sehingga menyebabkan komputer yang lain tidak mendapat jatah bandwidth yang adil. Padahal bagian Sales, Manager, dan direktur sangant membutuhkan akses internet yang stabil karena bagian Sales harus selalu memperbarui data - data produk perusahaan dan melakukan komunikasi dengan para pelanggan, sedangkan manager dan Direktur harus selalu siap dalam menerima informasi - informasi terbaru dari staff maupun dari kolega/rekanan kerjanya. Karena koneksi internet yang tidak merata hal ini menyebabkan terganggunya operasional perusahaan, sehingga berdampak pada ruginya perusahaan baik dari material maupun manajerial.

Belum adanya manajemen bandwidth pada CV Cahaya Indo Alumunium diperparah dengan banyaknya staff dan karyawan yang menggunakan internet tidak untuk mengakses kebutuhan yang berhubungan dengan pekerjaan. Masih banyak staff dan karyawan yang menggunakan internet untuk mengakses situs - situs social media seperti facebook, twitter maupun situs - situs lainnya yang tidak ada kaitannya dengan pekerjaan, membuat tidak efektifnya internet yang ada pada CV Cahaya Indo Alumunium tersebut.
Oleh sebab itu untuk memaksimalkan akses internet yang terdapat pada CV Cahaya Indo Alumunium diperlukan manajemen bandwidth dan filtering web access control. Dengan adanya manajemen bandwidth dan filtering web access control diharapkan semua komputer menggunakan internet dengan lancar dan stabil walaupun semua unit komputer menggunakan internet dalam waktu yang bersamaan, meningkatkan produktifitas staff/karyawan dalam bekerja, dan menurut Riadi (2010:381) mengatakan bahwa "Menerapkan limitas bandwidth menggunakan simple queues dapat memaksimalkan penggunaan bandwidth sehingga penggunaan layanan internet lebih optimal".

\section{Maksud dan Tujuan}

Maksud dari penulisan skripsi ini sebagai berikut:

1. Menganalisa permasalahan jaringan yang terdapat pada CV Cahaya Indo Alumunium.

2. Mengusulkan Implementasi Manajemen Bandwidth dan Filtering Web Access Control Menggunakan Metode Address List Pada CV Cahaya Indo Aluminium.

3. Memperkokoh keterkaitan dan kesepadanan (Link and match) antara kampus dengan dunia kerja.

\section{Metode Penelitian}

Analisa penelitian yang diperlukan dalam penyusunan skripsi ini adalah sebagai berikut:

1. Analisa Kebutuhan

Untuk melakukan penelitian tentang “ Implementasi Manajemen Bandwidth dan Filtering Web Access Control Menggunakan Metode Address List". Guna penyusunan skripsi ini, membutuhkan beberapa software dan beberapa hardware. Software yang dibutuhkan dalam penelitian ini adalah mikrotik RouterOS, Winbox, VirtualBox, Cisco Packet Tracer, dan Microsoft Office Visio. Sedangkan hardware yang dibutuhkan adalah satu buah laptop, dan satu buah Routerboard Mikrotik RB 750.

2. Desain

Desain jaringan yang akan digunakan dalam penelitian tentang " Implementasi Manajemen Bandwidth dan Filtering Web Access Control Menggunakan 
Metode Address List” guna penyusunan skripsi ini terdiri dari internet, router, switch, access point, dan client (baik wired maupun wireless). Desain jaringan ini merupakan pengembangan dari desain jaringan yang sebelumnya diterapkan pada CV Cahaya Indo Alumunium. Jika pada desain sebelumnya menggunakan dua buah route wireless, maka pada desain jaringan yang akan digunakan pada skripsi ini dua router wireless tersebut diganti dengan satu buah router mikrotik. Sekalipun hanya satu buah router, akan tetapi router ini memiliki banyak fitur yang jauh lebih lengkap dari dua router wireless yang sebelumnya diterapkan pada CV Cahaya Indo Alumunium. Pada desain ini juga terdiri dari satu buah external access point dan Sembilan buah komputer client.

3. Testing

Pengujian Implementasi Manajemen Bandwidth Dan Filtering Web Access Control Menggunakan Metode Address List dapat dikatakan berhasil jika bandwidth yang diterima user sesuai dengan apa yang disetting pada router mikrotik. Dan dikatakan berhasil jika user tidak bisa mengakses media sosial atau situs - situs yang dilarang oleh agama dan negara sesuai yang dikonfigurasi pada router mikrotik. Adapun untuk melakukan pengujian tersebut menggunakan oracle virtual box, virtual mikrotik router os, dan virtual windows $x p$.

4. Implementasi

Manajemen Bandwidth dan Filtering Web Access Control Menggunakan Metode Address List ini akan diterapkan pada CV Cahaya Indo Aluminium. Untuk menerapkannya membutuhkan satu perangkat router mikrotik, kemudian mengkonfigurasi manajemen bandwidth pada fitur simple queue dan mengkonfigurasi filtering web access control pada menu firewall yang terdapat pada router mikrotik tersebut

\section{Ruang Lingkup}

ruang lingkup pembahasan yang hanya membahas tentang Manajemen Bandwidth dan Filtering Web Access Control Menggunakan Metode Address List yang meliputi setting nama untuk setiap interface di router mikrotik, setting IP address untuk setiap interface di router mikrotik, setting gateway pada router mikrotik, setting DNS pada router mikrotik, setting NAT pada router mikrotik, setting manajemen bandwidth pada router mikrotik, setting address list pada router mikrotik, setting filtering web access control untuk blokir situs negative (porno), dan setting filtering web access control untuk blokir situs media sosial. Sedangkan untuk melakukan konfigurasi pada router mikrotik penulis menggunakan winbox versi 2.2.18.

\section{Tinjauan Pustaka}

Menurut Kurnianto, dkk (2013:57) mengatakan bahwa, "Jaringan Komputer adalah sekumpulan komputer yang saling terhubung satu sama lain dan bekerja secara otomatis. Hal yang dapat mempengaruhi kestabilan koneksi internet yaitu besarnya Bandwidth yang digunakan jaringan tersebut dan seberapa efektif Bandwidth tersebut bisa dimanfaatkan".

Dan menurut Fitriastuti, dkk (2014:3) mengatakan bahwa, "Bandwidth adalah besaran untuk menunjukkan seberapa banyak data yang dapat dilewatkan dalam koneksi melalui sebuah network (Vektanova, 2003). Bandwidth disebut juga lebar pita atau kapasitas saluran informasi yaitu kemampuan maksimum dari suatu alat untuk menyalurkan informasi dalam satuan waktu detik".

\section{Konsep Dasar Jaringan}

Menurut Sutedjo mengatakan bahwa "Jaringan komputer adalah sekelompok otonom yang saling menggunakan protokol komunikasi melalui media komunikasi sehingga dapat berbagi data, informasi, program, aplikasi, dan perangkat keras seperti printer, scanner, $C D$-drive ataupun hardisk, serta memungkinkan berkomunikasi secara elektronik".

Adapun menurut Wahana Komputer (2010:2), "Jaringan komputer adalah sebuah sistem yang terdiri atas komputer dan perangkat jaringan yang bekerja bersama sama untuk mencapai suatu tujuan yang sama”. Sedangkan menurut Arifin (2011:9) "Jaringan komputer merupakan kumpulan dari beberapa komputer yang terhubungkan satu dengan yang lainnya dengan menggunakan protokol komunikasi". Berdasarkan luas wilayah, jaringan dibedakan menjadi 3 bagian, yaitu:

\section{Local Area Network (LAN)}


Merupakan jaringan yang menghubungkan sejumlah komputer yang ada dalam suatu lokasi yang terbatas. Biasanya diterapkan untuk jaringan komputer rumahan, laboratorium, komputer disekolah dan kantor, dimana masing - masing komputer dapat saling berinteraksi, bertukar data, dan dapat menggunakan peralatan bersama, seperti printer. LAN dapat menggunakan media komunikasi seperti kabel dan wireless.

\section{Metroplitan Area Network (MAN)}

Merupakan jaringan yang lebih besar dari jaringan LAN tetapi lebih kecil dari jaringan WAN. Jaringan MAN dan jaringan WAN sama - sama menghubungkan beberapa LAN yang membedakan hanya lingkup areanya yang berbeda. Media yang digunakan idealnya adalah wireless atau kabel serat optic. Namun, untuk menghemat biaya, biasanya perusahaan memanfaatkan media komunikasi umum yang sudah ada. Dengan menggunakan jaringan metropolitan, perusahaan atau lembaga tertentu dapat dengan cepat dan mudah memperoleh informasi dan data yang dibutuhkan.

\section{Wide Area Network (WAN)}

Merupakan jaringan yang menghubungkan natar LAN yang berada berjauhan, cakupan WAN bisa sampai negara, benua atau mencakup geografis yang sasngat luas. Pada jaringan WAN biasanya terdapat protokol TCP/IP yang digunakan untuk kombinasi dengan perangkat seperti switch, router, dan lain - lain. Dengan WAN, pertukaran data dan komunikasi antar pengguna lebih cepat, tepat, dan murah. Kumpulan dari berbagai WAN akan membentuk internetworking atau yang biasa disebut dengan internet. Dengan menggunakan internet, setiap orang bisa dengan mudah dan cepat mengakses dan memperoleh informasi - informasi terbaru dari berbagai belahan dunia.

\subsection{Peralatan Pendukung}

Peralatan pendukung yang dibutuhkan untuk melakukan implementasi manajemen Bandwidth dan filtering web access control menggunakan metode address list pada suatu sistem jaringan komputer terdiri dari software dan hardware. Diantara software yang dibutuhkan adalah Mikrotik RouterOS, Winbox, VirtualBox, Cisco Packet Tracer, dan Routerboard mikrotik

\section{ANALISA PERANCANGAN Rancangan Aplikasi}

Rancangan aplikasi ini membahas langkah - langkah konfigurasi manajemen bandwidth dan filtering web access control yang akan diterapkan pada CV Cahaya Indo Alumunium. Adapun langkah-langkah konfigurasinya adalah sebagai berikut:

1. Setting nama untuk setiap interface di router mikrotik

[admin@Router-CIA] > interface set etherl name $=$ Ethl Public

[admin@Router-CIA] > interface set ether2 name=Eth2 Local

[admin@Router-CIA] > interface set ether3 name=Eth3 Hotspot

2. Setting IP Address untuk setiap interface di router mikrotik

[admin@Router-CIA] > IP Address add address $=192.168 .0 .2 / 24$ interface $=$ Eth 1 Public

[admin@Router-CIA] > IP Address add address $=192.168 .100 .1 / 24$ interface $=$ Eth2 Local

[admin@Router-CIA] > IP Address add address $=192.168 .10 .1 / 24$ interface $=$ Eth3 Hotspot

3. Setting gateway pada router mikrotik

[admin@Router-CIA] > ip route add dstaddress $=0.0 .0 .0 / 0$ gateway $=192.168 .0 .1$ distance $=1$ check-gateway $=$ ping

4. Setting DNS pada router mikrotik 
[admin@Router-CIA] > ip dns set

servers $=$

180.131.144.144,180.131.145.145

\section{Setting NAT pada router mikrotik}

[admin@Router-CIA] > ip firewall nat add chain $=$ srcnat out-interface $=$ Public action $=$ masqueraade

\section{Setting manajemen bandwidth pada router mikrotik}

[admin@Router-CIA] > quеиe simple add name $=$ Direktur target addresses $=192.168 .100 .10$ max limit $=1000000 / 2000000$

[admin@Router-CIA] > queue simple add name $=$ Office Manager target addresses $=192.168 .100 .20$ max limit $=512000 / 1000000$

[admin@Router-CIA] > queue simple add name $=$ Project Manager target addresses $=192.168 .100 .21$ max limit $=512000 / 1000000$

[admin@Router-CIA] > queue simple add name $=$ Sales target addresses $=192.168 .100 .22$ max limit $=512000 / 1000000$

[admin@Router-CIA] > quеие simple add name $=$ Sales 2 target addresses $=192.168 .100 .23$ maxlimit $=512000 / 1000000$

[admin@Router-CIA] > queue simple add name $=$ Quality Control target addresses $=192.168 .100 .24$ maxlimit $=512000 / 1000000$

[admin@Router-CIA] > quеие simple add name $=$ Keuangan target addresses $=192.168 .100 .25$ max limit $=512000 / 1000000$

[admin@Router-CIA] > queue simple add name $=A D M$ target addresses $=192.168 .100 .26$ max limit $=512000 / 1000000$
[admin@Router-CIA] > queue simple add name $=$ Warehouse target addresses $=192.168 .100 .27$ max limit $=512000 / 1000000$

[admin@Router-CIA] > queue simple add name $=$ Hotspot target addresses $=192.168 .10 .0 / 24$ max limit $=512000 / 1000000$

7. Setting address list pada router mikrotik [admin@Router-CIA] > ip firewall address-list add list=Direktur address $=192.168 .100 .10$ comment $=I P$ Direktur

[admin@Router-CIA] > ip firewall address-list add list=Karyawan address $=192.168 .100 .20$ comment $=$ IP Karyawan

[admin@ Router-CIA] > ip firewall address-list add list=Karyawan address $=192.168 .100 .21$ comment=IP Karyawan

[admin@Router-CIA] > ip firewall address-list add list=Karyawan address $=192.168 .100 .22$ comment $=$ IP Karyawan

[admin@Router-CIA] > ip firewall address-list add list=Karyawan address $=192.168 .100 .23$ comment $=I P$ Karyawan

[admin@Router-CIA] > ip firewall address-list add list=Karyawan address $=192.168 .100 .24$ comment $=$ IP Karyawan

[admin@Router-CIA] > ip firewall address-list add list=Karyawan address $=192.168 .100 .25$ comment $=$ IP Karyawan

[admin@Router-CIA] > ip firewall address-list add list=Karyawan address $=192.168 .100 .26$ comment=IP Karyawan 
[admin@Router-CIA] > ip firewall

address-list add list=Karyawan

address $=192.168 .100 .27$ comment=IP

Karyawan

[admin@Router-CIA] > ip firewall address-list add list=Karyawan address $=192.168 .10 .0 / 24$ comment $=$ IP

Karyawan

8. Setting filtering web access control untuk blokir situs negative (porno)

[admin@Router-CIA] > ip firewall mangle chain=forward content $=$ porn action $=$ mark-packet new-packet mark=blokir

[admin@Router-CIA] > ip firewall mangle chain $=$ forward content $=$ seks action $=$ mark-packet new-packet mark=blokir

[admin@Router-CIA] > ip firewall mangle chain $=$ forward content $=$ sex action $=$ mark-packet new-packet mark=blokir

[admin@Router-CIA] > ip firewall filter add chain=forward packet - mark=blokir action $=$ drop

9. Setting filtering web access control untuk blokir situs media sosial

[admin@Router-CIA] > ip firewall layer7-protocol add name=blok_facebook regexp $=\wedge$. $*($ facebook $) * \$$

[admin@Router-CIA] > ip firewall layer7-protocol add name=blok_twitter regexp $=\wedge$.*(twitter).*\$

[admin@Router-CIA] > ip firewall layer7-protocol add name=blok_skype regexp $=^{\wedge}$.*(skype $) * \$$

[admin@Router-CIA] > ip firewall layer7-protocol add name=blok_youtube regexp $=^{\wedge} . *$ (youtube). $* \$$
[admin@Router-CIA] > ip firewall filter add chain=forward layer7-

protocol=blok_facebook protocol=tcp dst-port $=80,443$ action $=$ drop

[admin@Router-CIA] > ip firewall filter add chain=forward layer7protocol=blok_skype protocol=tcp dstport $=80,443$ action $=$ drop

[admin@Router-CIA] > ip firewall filter add chain=forward layer7protocol=blok_youtube protocol=tcp dstport $=80,443$ action $=\mathrm{drop}$

[admin@Router-CIA] > ip firewall filter add chain=forward layer7-

protocol=blok_twitter protocol=tcp dstport $=80,443$ action $=$ drop

\subsection{Manajemen Jaringan}

Tindakan yang diperlukan dalam melakukan manajemen jaringan untuk mendukung penerapan manajemen bandwidth dan filtering web access control pada CV Cahaya Indo Alumunium adalah sebagai berikut:

1. Melakukan monitoring jaringan melalui logs yang terdapat pada router mikrotik dengan menggunakan software winbox.

2. Melakukan penjadwalan untuk merestart router secara berkala agar performa router dapat selalu terjaga.

3. Melakukan backup terhadap konfigurasi yang terdapat pada router mikrotik sebagai antisipasi jika suatu saat router mikrotiknya mengalami kegagalan fungsi

4. Menggunakan winbox untuk memastikan semua konfigurasi manajemen bandwidth dan filtering web access control pada router mikrotik berjalan dengan baik.

5. Memastikan seluruh elemen utama (internet, router, switch, komputer) dan elemen pendukung listrik, pendingin ruangan server) yang terdapat pada jaringan komputer dapat berjalan dengan baik.

\section{PENGUJIAN}

\section{Pengujian Jaringan Awal}

Pengujian jaringan awal ini akan membahas pengujian terhadap jaringan berjalan yang terdapat pada CV Cahaya Indo 
Alumunium, dimana pada jaringan ini belum menerapkan manajemen bandwidth dan filtering web access control. Untuk melakukan pengujian terhadap jaringan yang sedang berjalan, yaitu dengan cara melakukan speedtest bandwidth, yang dalam hal ini menggunakan alamat http://speedtest.cbn.net.id sebagai penyedia layanan speedtestnya. Selain melakukan pengujian terhadap speedtest juga dilakukan pengujian untuk melakukan akses ke situs situs negative dan situs - situs media sosial. Dari pengujian yang dilakukan didapatkan hasil sebagai berikut:

1. Pengujian jaringan sebelum terdapat manajemen bandwidth

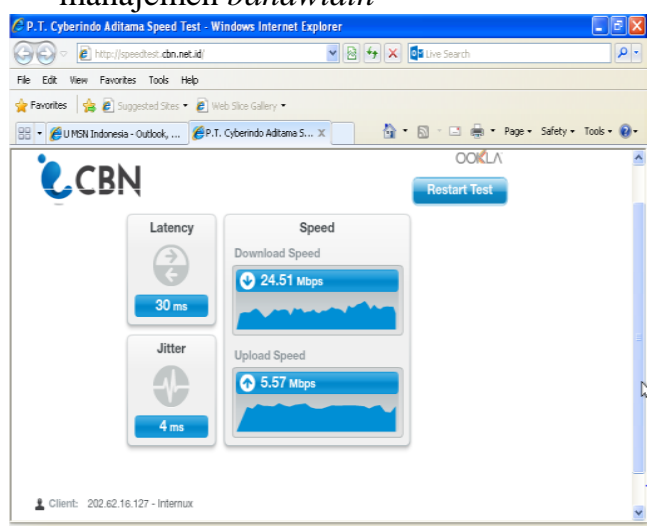

Sumber: Dokumen Pribadi

Gambar IV.1 Pengujian jaringan dengan melakukan speedtest

Pada gambar IV.1 diatas memperlihatkan bahwa salah satu client mendapatkan bandwidth yang terlalu besar, padahal bandwidth keseluruhan yang terdapat pada CV Cahaya Indo Alumunium untuk downloadnya $25 \mathrm{Mbps}$ dan untuk uploadnya 6 Mbps, itu artinya hampir keseluruhan bandwidth digunakan oleh satu client/karyawan saja. Untuk masing masing client/karyawan seharusnya cukup 1 Mbps untuk downloadnya dan 512 Kbps untuk uploadnya.

2. Pengujian jaringan sebelum menerapkan filtering web access control

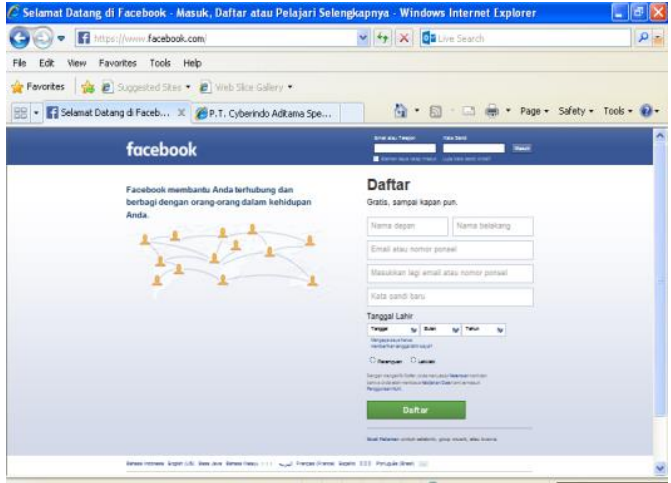

Sumber: Dokumen Pribadi

Gambar IV.2 Pengujian jaringan dengan melakukan akses ke facebook

Pada gambar IV.2 dapat terlihat bahwa salah satu client masih bisa mengkases situs - situs media sosial, yang dalam contoh diatas karyawan masih bisa mengkases facebook. Hal tersebut tentu akan mempengaruhi produktifitas karyawan dalam bekerja. Karena dengan masih bisanya mengakses situs - situs media sosial akan membuat karyawan menjadi tidak focus dalam bekerja.

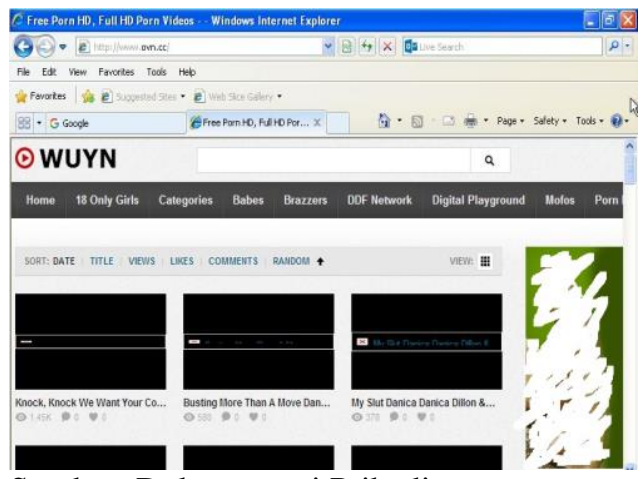

Sumber: Dokumentasi Pribadi

Gambar IV.3 Pengujian jaringan dengan melakukan akses kesitus negatif

Sedangkan dari gambar IV.3 dapat kita lihat bahwa client masih bisa mengakses situs - situs negative (situs porno). Sehingga dari hasil pengujian diatas dapat diambil kesimpulan bahwa sistem jaringan komputer yang belum menerapkan manajemen bandwidth dan filtering web access control tidak mampu membatasi dan mengatur bandwidth yang digunakan oleh client/karyawan serta tidak dapat membatasi client/karyawan dalam mengakses situs situs negative dan situs - situs media sosial.

\subsection{Pengujian Jaringan Akhir}


Pengujian jaringan akhir ini akan membahas pengujian terhadap jaringan yang diusulkan untuk diterapkan pada CV Cahaya Indo Aluminium, dimana pada jaringan ini sudah menerapkan manajemen bandwidth dan filtering web access control . untuk melakukan pengujian terhadap jaringan yang diusulkan, yaitu dengan cara melakukan speedtest bandwidth, yang dalam hal ini menggunakan alamat http://speedtest.cbn.net.id sebagai penyedia layanan speedtestnya. Selain melakukan pengujian terhadap speedtest juga dilakukan pengujian untuk melakukan akses ke situs situs negative dan situs situs media sosial. Dari pengujian yang dilakukan didapatkan hasil sebaagai berikut:

Pengujian jaringan setelah menerapkan manajemen bandwidth

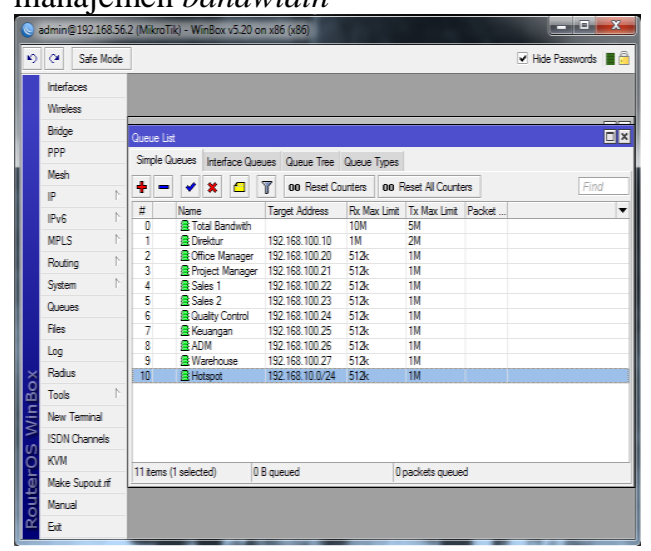

Sumber: Dokumen Pribadi

Gambar IV.4 Konfigurasi manajemen bandwidth pada mikrotik

Pada gambar IV.4 diatas memperlihatkan hasil konfigurasi manajemen bandwidth yang dilakukan pada router mikrotik untuk diterapkan pada jaringan CV Cahaya Indo Aluminium.

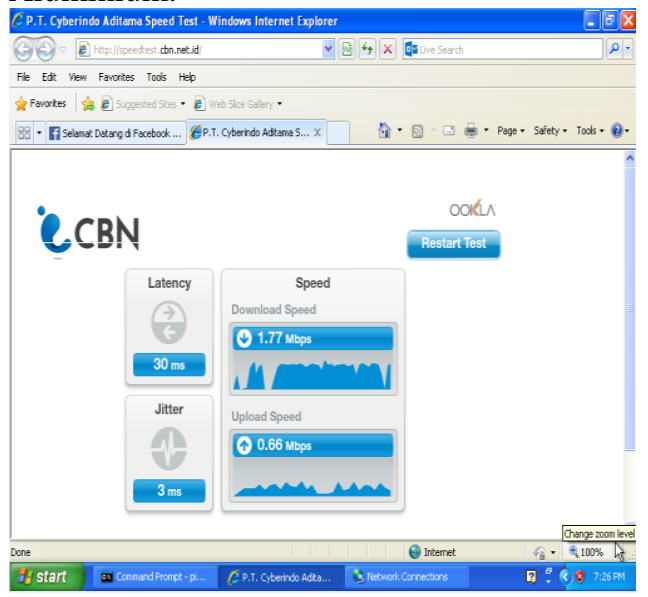

Sumber: Dokumentasi Pribadi
Gambar IV.5 Hasil speedtest pada komputer direktur

Berdasarkan gambar IV.5 diatas merupakan hasil speedtest yang dilakukan pada komputer direktur. Dari gambar tersebut memperlihatkan hasil yang sesuai dengan konfigurasi manajemen bandwidth yang dilakukan pada router mikrotik bahwa direktur diberikan bandwidth sebesar 2 Mbps untuk downloadnya dan 1 Mbps untuk uploadnya, dan berdasarkan hasil speedtest pada gambar diatas direktur mendapat bandwidth 1,77 Mbps untuk downloadnya dan 0,66 Mbps untuk uploadnya.

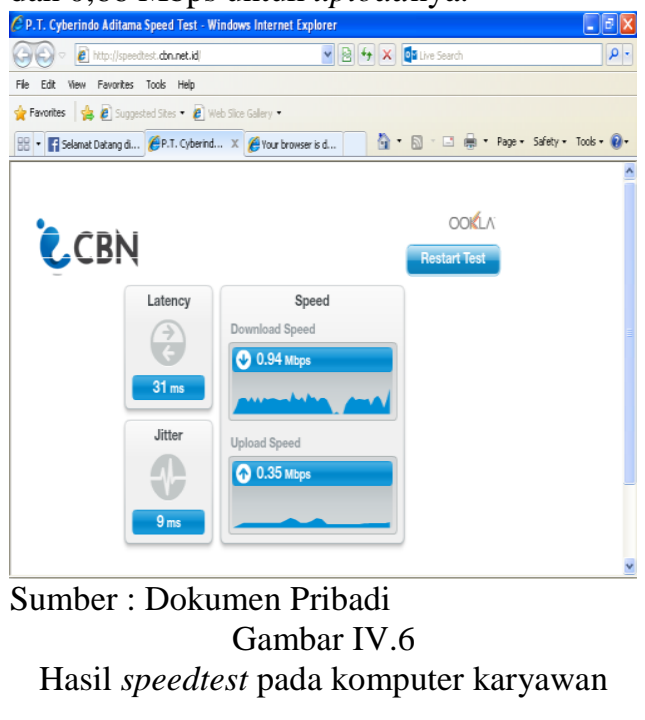

Pada gambar IV.6 diatas merupakan hasil speedtest yang dilakukan pada salah satu komputer karyawan. Dari gambar tersebut memperlihatkan hasil yang sesuai dengan konfigurasi manajemen bandwidth yang dilakukan pada router mikrotik bahwa karyawan mendapat bandwidth sebesar 1 Mbps untuk downloadnya dan 512 Kbps untuk uploadnya dan berdasarkan hasil speedtest pada gambar diatas karyawan mendapat bandwidth 094 Mbps untuk downloadnya dan 0,35 Mbps untuk uploadnya.

1. Pengujian jaringan setelah dilakukan filtering web access control 


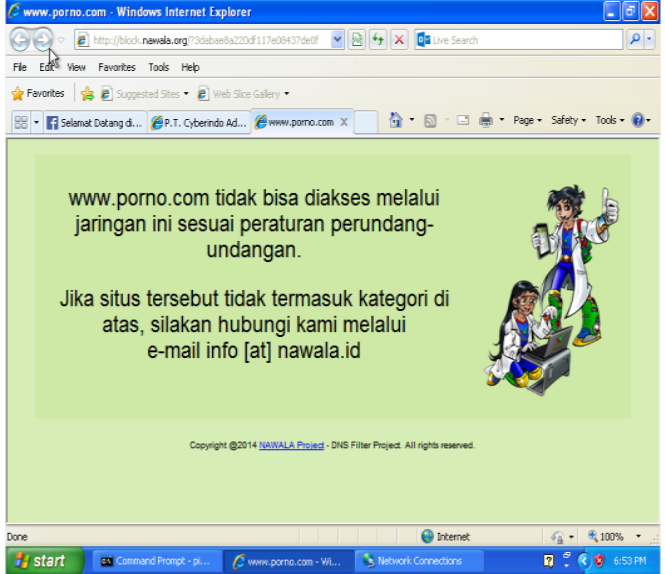

Sumber: Dokumen Pribadi

Gambar IV.7

Hasil pengujian filtering web access control saat mengunjungi situs porno

Pada gambar IV.7 dapat dilihat hasil pengujian jaringan saat mencoba mengakses situs negative (situs porno), dari gambar tersebut terlihat bahwa client/karyawan tidak bisa mengakses situs negative tersebut, hal tersebut terjadi karena sudah dilakukan filtering web access control pada router mikrotik yang tidak mengizinkan client/karyawan untuk mengakses situs situs negative termasuk didalamnya situs porno.

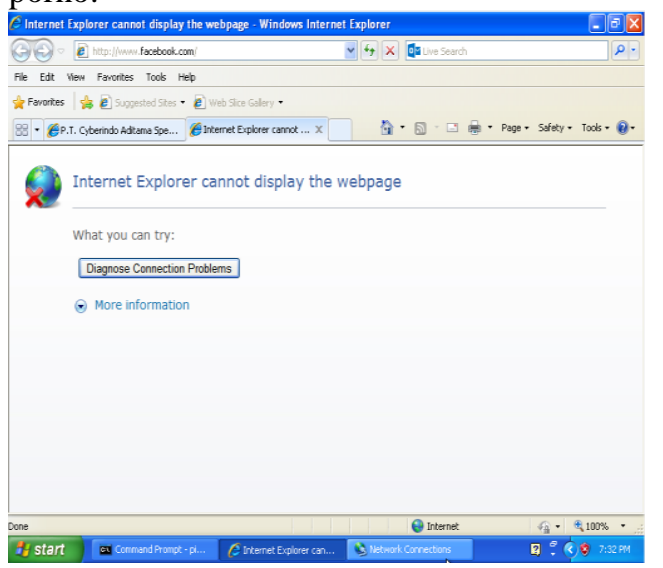

Sumber: Dokumetasi Pribadi

Gambar IV.8

Hasil pengujian filtering web access control saat mengunjungi situs media sosial

Berdasarkan gambar IV.8 dapat dilihat hasil pengujian jaringan saat mencoba mengakses situs media sosial, disana terlihat bahwa client/karyawan tidak bisa mengakses situs media sosial tersebut, hal tersebut terjadi karena sudah dilakukan filtering web access control dengan menggunakan filtering firewall yang dikonfigurasikan pada router mikrotik.

\section{Kesimpulan}

Berdasarkan implementasi manajemen bandwidth dan filtering web access control menggunakan metode address list yang penulis lakukan pada CV Cahaya Indo Aluminium. Maka penulis dapat menarik kesimpulan sebagai berikut:

1. Sistem jaringan komputer yang sudah menerapkan manajemen bandwidth dan filtering web access control mampu mengatur bandwidth internet yang digunakan pada suatu sistem jaringan komputer dan mampu membatasi akses ke situs - situs negative dan situs - situs media sosial.

2. Menerapkan manajemen bandwidth dan filtering web access control akan membuat karyawan lebih produktif damalam bekerja, sehingga akan menguntungkan bagi perusahaan. Karena karyawan tidak bisa mengakses situs - situs negative dan situs - situs media sosial.

3. Filtering web access control menggunakan address list dapat meningkatkan efisiensi didalam menggunakan resource pada router mikrotik, hal ini dikarenakan cara kerja address list mengelompokkan beberapa IP address menjadi satu, sehingga akan menghemat script (pengaturan), berbeda halnya jika pengaturan filtering web access control dilakukan secara satu persatu (satu ip satu pengaturan), hal ini akan memerlukan banyak script (pengaturan) yang akibatnya akan menaikkan CPU load pada router mikrotik, sehingga kerja router menjadi tidak maksimal dan akan mempengaruhi kinerja jaringan secara keseluruhan.

\section{Saran}

Saran yang penulis dapat berikan untuk mendukung implementasi serta pengembangan manajemen bandwidth dan filtering web access control menggunakan metode address list, antara lain:

1. Untuk mempermudah konfigurasi manajemen bandwidth, bisa dibuat aplikasi untuk mengatur bandwidth dengan model GUI (grapich user interface) seperti winbox.

2. Manajemen bandwidth yang diterapkan pada jaringan yang berskala besar sebaiknya menggunakan metode Quеие 
Tree dan menggunakan router yang mempunyai spesifikasi tinggi agar tetap dapat memberikan resource terhadap implementasi manajemen bandwidth.

3. Untuk melakukan pemblokiran terhadap situs - situs negative dan situs - situs media sosial selain menggunakan fitur filtering layer 7 protocols yang terdapat pada router mikrotik dapat menggunakan web proxy yang terdapat pada router mikrotik.

\section{DAFTAR PUSTAKA}

[1]. Arifin, Hasnul. 2011. Kitab Suci Jaringan Komputer dan Koneksi Internet. Yogyakarta: Mediakom.

[2]. Fitriastuti, Fatsyahrina dan Dodi Prasetyo Utomo. 2014. Implementasi Bandwidth Management dan Firewall System Menggunakan Mikrotik OS 2.9.27. ISSN: 2088-3676. Yogyakarta: Jurnal Teknik. Vol 4 No. 1, April 2014.

[3]. Kurnianto, Catur Andi dkk. 2013. Manajemen Bandwidth Menggunakan Delay Pools di Squid Proxy (Studi Kasus : SMAN 1 Sragen). ISSN: 23386313. Yogyakarta: Jurnal JARKOM. Volume 1 No. 1, Desember 2013: 57-65

[4]. Kurniawan, Wiharsono. 2007. Computer Starter Guide Jaringan Komputer. Yogyakarta: Penerbit Andi.

[5]. Madcoms. 2010. Panduan Lengkap Membangun Sistem Jaringan Komputer. Yogyakarta: Penerbit Andi.

[6]. Riadi, Imam. 2010. Optimasi Bandwidth Menggunakan Traffic Shapping. Yogyakarta: Jurnal Informatika. Volume 4 No 1, Januari 2010: 374-382. 